Article

\title{
Meetings Between Professionals for the Inclusion of Children in Citizen Participation: A Formative Experience
}

\author{
Ana M. Novella Cámara ${ }^{1}$, Ferran Crespo i Torres ${ }^{1, *}$, and Héctor Pose Porto ${ }^{2}$ \\ ${ }^{1}$ Department of Theory and History of Education, University of Barcelona, Spain \\ ${ }^{2}$ Department of Pedagogy and Didactics, University of A Coruña, Spain \\ * Corresponding author (f.crespoitorres@ub.edu)
}

Submitted: 29 October 2021 | Accepted: 21 December 2021 | Published: 20 April 2022

\begin{abstract}
Municipalities must take steps towards an "educational action" that welcomes children into environments that estimulate their involvement and participation in issues that mean something to them. Professionals working directly with children in the municipal sphere must strengthen the development of their active and committed citizenship (SDG no. 4), relating to them as citizens capable of transforming their environment. Children's participation requires adults who recognise them as interlocutors and establish relationships of trust and mutual respect with them. Municipalities need to create opportunities for children to be included in the co-production of local projects and to take a leading role in public policies. This article aims to offer elements that can nurture professionals' readiness and "capacity building" to facilitate children's participation. These elements are formed in the context of a pedagogical practice (the "coffee meetings") and emerge through a systematisation of experiences (Aguiar, 2013; Barnechea \& Morgan, 2010; Jara, 2012, 2018; Mera, 2019). Coordinated by an inter-university team, the reflective exchange promoted by the meetings between municipal technical professionals and elected representatives generates knowledge, ideas, and changes in participants' approaches to children's participation in municipalities' decision-making processes; content analysis, development, and evaluation of the meetings by participants provide insight into the value of a learning community established as a tool to innovate child participation, build professional capacity towards this goal, and strengthen the work of local administrations in the field of citizenship.
\end{abstract}

\section{Keywords}

children and adolescents; citizen action; experience; inclusion; municipality; participation

Issue

This article is part of the issue "Promoting Social Inclusive Experiences in Uncertain Times" edited by Ana Belén Cano-Hila (University of Barcelona).

(C) 2022 by the author(s); licensee Cogitatio (Lisbon, Portugal). This article is licensed under a Creative Commons Attribution 4.0 International License (CC BY).

\section{Introduction}

The complexity of local social realities emphasises the need for putting arguments and political programmes into action. Innovative meanings are consequently given to words that appeal to social participation, youth empowerment, social justice and equity, lifelong learning, etc., all of which are fundamental to making the local space a hub for policymaking. In most municipalities, this fact has changed the role of the local authorities on behalf of a better development of people and communities by becoming a relational administration. These administrations focus on the reduction of the conditions of vulnerability and the improvement of the living conditions of all citizens. The 2030 agenda for sustainable development, approved by the UN in 2015, offers local administrations a framework to combat and reduce poverty, reduce inequalities, protect the planet, and improve people's living conditions. To this end, SDG no. 4, "to ensure inclusive and equitable quality education and promote lifelong learning opportunities for all," is key. However, it certainly needs to be harmonised with 
target 16.7 of SDG no. 16, which states: "Ensure responsive, inclusive, participatory and representative decisionmaking at all levels." Promoting an active, inclusive, and governance-engaged citizenry promotes democratic and sustainable communities. This article aims to strengthen the role of children as active citizens who participate in municipal decision-making.

This article argues that a competent adult capable of recognising children's citizenship will be able to broaden their opportunities to participate in the city. Professionals' formative experience should be based on and progress according their needs. Our intention is to contribute to overcoming the conception of children as an invisible and vulnerable group to achieve a conception of children that recognises them as capable of taking co-responsibility for their environment and their community and shape a more inclusive society.

\subsection{Municipalities as Educational Agencies}

The leadership of municipalities as territorial entities and subsidiary administrations is indisputable in improving citizens' quality of life (Pose \& Caride, 2019). The most proactive municipalities have set themselves up as true educational agencies, which do not leave the education of their citizens to chance. The firm commitment of a few cities to mainstream the principle of education and culture as the hallmarks of their political initiative led to the emergence of the International Association of Educating Cities (IAEC) in 1990. The movement began to differentiate education from schooling from the outset, opening up to more holistic and integrative perspectives on lifelong citizenship education, involving multiple actors and in diverse contexts. Among its principles was promoting the city as an educational agent and space and, above all, recognise that the city can be transformed through education. The city is understood as the space of public affairs, the opportunity for access to socialisation, equality or freedoms, public goods, work, social relations and exchanges, culture and leisure, participation, solidarity, and the exercise of democracy. Thirty years after the emergence of the Educating Cities movement, its renewed Charter advocates in the preamble for an autonomous, committed, and supportive citizenship, capable of living together in difference, of taking part in its community, of seeking peaceful solutions to conflicts, in short, a citizenship that is aware of the challenges facing humanity and co-responsible for the solutions.

The diversity of possibilities that emerge for municipal workers with socio-educational sensitivity is enough to achieve an educational labour that searches the maximum appropriation degree of the city by its citizens. The role of the municipality as an educational and local administration extends to areas that encompass all the citizenship: in school or informal contexts, in educational times such as leisure and social interaction, in training tasks like knowledge updating, sensitization, or as civic pedagogy. The approach to the
SDGs by local governments requires social innovation and citizen participation. Only through collaboration and mutual co-responsibility will it be possible to promote the empowerment and sustainability of communities (Dos Santos Figueiredo et al., 2018).

The city requires citizen participation as an indispensable condition. It requires the exercise of citizenship in the face of collective commitments (Giménez Romero, 2020; Subirats, 2008). This process also implies a city that forms a culture of citizenship that empowers its citizens and enables them to exercise their right to take part in public decisions. Del Pozo (2020, p. 98) summarised the concept of civic culture in four basic notions: interpersonal respect, responsibility, valuing that which is public, and ethical-political commitment. This last notion reinforces the need for a participatory basis in the city, charged with a sense of ethics and political will, to optimise all citizens' living conditions.

\subsection{Inclusion of Children in Citizen Participation}

In recent years, participatory democracy and citizen participation have emerged as socio-cultural challenges to promote an active citizenry committed to the governance and leadership of their collective and community projects. However, underneath this conviction lies the violation of the rights of vulnerable groups such as children. The exclusion of children in the city means that their citizenship is denied, postponed or, at best, limited to being heard. An image of childhood as a life stage preparatory to adulthood continues to be forged, characterised by the stigma of immaturity, innocence, inexperience, and insufficient knowledge; participation conditional on age, maturity, and voice (Wyness, 2013) is anchored by its future value-arguments based on which citizenship for children has been dismissed. According to Wilks and Rudner (2013), children must be recognised for who they are in the present in terms of their diversity, potentials, knowledge, and experiences, as no other citizen group can replace them.

The representation of children begins to shift considerably from its political place following the adoption of the United Nations Convention on the Rights of the Child (CRC). Subsequently, UN General Comment no. 12 on "the right of the child to be heard" (CRC, 2009) and UN General Comment no. 20 on the implementation of children's rights during adolescence (CRC, 2016) are reference frameworks for promoting children's political participation. Children need active practices from which they can be incorporated into processes where they can participate and creatively appropriate participatory procedures and strategies. Participation in these practices entails a process of self-assessment, as well as constant attention on learning for change and social transformation, as is required by all participatory action research (Percy-Smith, 2018).

At the same time, inspiring initiatives arose in the late 1990s and early 2000s: experiences like the Children's 
City in Fano (Italy), by the pedagogue Francesco Tonucci, or the Agenda 21 for Child-Friendly Culture or Cities, which combine the understanding of child participation as a substantive right that must be naturalised and gain presence in the everyday life of children in any of the contexts of the educational ecosystem. These initiatives provide an opportunity for addressing children's rights not only in their legal form but also in their interaction with children's ideas about their rights in local contexts (Liebel, 2020, p. 219) and the opportunities they create to transform their environment.

Child participation is a responsibility of local governments in the framework of the 2030 agenda and from the commitment to the inclusion of children as active citizens. Investing resources and programmes in pedagogical initiatives for participatory democracy based on the co-responsibility of children and adolescents for the common good transforms their being in the world and their communities. Cultivating children's participation generates benefits in terms of democratic culture and individual competencies: to critically understand reality; to communicate, dialogue and listen better; to cooperate and take co-responsibility (Trilla \& Novella, 2011). Only by including children as active citizens is it possible to govern, mitigate, and satisfy dramatic emerging social needs and improve the living conditions of all. If those in power and their technical professionals approach children and activate cooperative actions, this will foster the achievement of an educating, democratic city. According to Rudner (2017, p. 204):

Participation enables children/young people to inform professionals and other stakeholders about their successes, struggles, and aspirations for their lives. When acted upon, children/young people can contribute to better policies that improve health, education, legal rights and safety and reduce discrimination and violence.

There is a global movement for the inclusion of children's participation, but it needs to break down barriers and resistance to gain sufficient strength to influence local government policies that conceive children as naturalised citizens (Moosa-Mitha, 2019). As well as accompanying the inclusion of children's participation as a political and educational citizenship process, going beyond being a formative requirement. Save the Children Sweden (2020) mapped child participation initiatives in 14 countries in regional programs in Latin America and the Caribbean, Eastern and Southern Africa, and Europe, providing diverse structures and forms of participation. Tools such as the Handbook on Children's Participation for Professionals Working for and With Children (Crowley et al., 2021), in collaboration with the Council of Europe's Children's Rights Division, offer elements to overcome these constraints and provide keys for professionals to work with children for positive, ethical, and effective participation that has an impact in their community. This material points to the need for professional capacity building for children's inclusion at all levels to bridge the gaps between participation recommendations and opportunities generated at all municipal levels. The notion set by Percy-Smith et al. (2019, p. 198) that "cooperation and dialogue between young people and adult-professionals are essential if young people are to achieve a sense of inclusion as equal citizens" poses a challenge that can only be answered by professionals relating to children through trust and recognition.

This article offers an analysis of meetings between professionals during the period of the Covid-19 pandemic, which began amid strict confinement measures. These meetings took the form of a learning community on the culture of child participation at the local level. The reconstruction of this experience makes it possible to identify how to better support professionals in strengthening their capacities to understand and develop the inclusion of children in municipal affairs by internalizing child participation as a continuous, ethical process, with repercussions but, above all, as an inclusive process.

\section{Context of the Study and Research Method}

The data included in this article come from an experience that arose at the beginning of the pandemic in the framework of the research project Childhood and Participation: Diagnosis and Proposals for Active and Inclusive Citizenship in the Community, Institutions, and Governance. This project aims to determine the state of child participation in Spain and to approach the components that make the inclusion of children in citizen participation possible through a participatory diagnosis. The project started at the beginning of 2019; at the end of January 2020, a collection of data was launched using a questionnaire technique with elected officials and municipal technicians to explore the state of child participation in Spanish municipalities belonging to the IAEC and UNICEF Child-Friendly Cities (CAI-UNICEF). At the end of February, due to the health emergency, everything came to a standstill.

Due to Covid-19 pandemic, the Spanish population, as in so many other countries, was strictly confined from March to June 2020. Jobs, health, economic and spatial resources, social relations, among others, were altered. Local administrations were exposed to high stress because of social control measures, the lack of assistance and operational resources, and the need for taking decisions straight away.

The pandemic displaces the efforts of municipal technicians to accompany situations of vulnerability aggravated by the dramatic circumstances arising from the pandemic context. Data collection slows down or even grinds to a halt. In this context, the research team asks itself what it can contribute to overcoming the moment's uncertainty.

As part of the research team, we found ourselves not giving up on our prospective approach to the object of 
study, questioning what to do so that the inclusion of children as participatory citizens in their environment does not take a step backwards. These are times when children are forbidden to move around the city and organised groups of boys and girls do not meet, so municipal technicians must consider how to continue accompanying them and including them in the exercise of their citizenship. This concern was shared with the IAEC and CAI-UNICEF partners, and the idea of organising a virtual meeting place was born with a double purpose: on the one hand, to have a space of assembly, empathy, and solidarity where we could share how to keep facilitating the participation of children in the municipalities; and on the other hand, to give local visibility to the issue of child and adolescent participation even in such exceptional circumstances.

This space was called "Let's Have a Coffee \#participatorychildhood." It was first convened on 17 April 2020 and developed into weekly meetings for the first two months, moving on to fortnightly and monthly meetings. At the time of writing, 15 90-minute meetings on different themes have been held. Table 1 shows the date, theme, and attendance rate of each "coffee meeting." The space has evolved over time, becoming consolidated as a monthly meeting point for the community to share and contribute different points of view on the participation and inclusion of children and adolescents in municipalities. Participants have been male and

Table 1. Regularity of the meeting, topics addressed, registrations, and attendance.

\begin{tabular}{|c|c|c|c|c|c|}
\hline & Date & Coffee meeting theme & $\begin{array}{l}\text { No. } \\
\text { registrations }\end{array}$ & $\begin{array}{l}\text { Approx. no. } \\
\text { of attendees }\end{array}$ & $\begin{array}{l}\text { No. of } \\
\text { participants }\end{array}$ \\
\hline 1 & $17 / 04 / 2020$ & $\begin{array}{l}\text { Shall we have a coffee while sharing challenges } \\
\text { on \#participatorychildhood in times of Covid-19? }\end{array}$ & $\mathrm{X}$ & 55 & $\mathrm{x}$ \\
\hline 2 & $24 / 04 / 2020$ & Participation and the digital divide & 85 & 62 & 9 \\
\hline 3 & $08 / 05 / 2020$ & $\begin{array}{l}\text { Participation and summer activities in times } \\
\text { of Covid-19 }\end{array}$ & 153 & 97 & 14 \\
\hline 4 & $15 / 05 / 2020$ & $\begin{array}{l}\text { Participation and summer activities in times } \\
\text { of Covid-19 (II) }\end{array}$ & 127 & 98 & 13 \\
\hline 5 & $22 / 05 / 2020$ & $\begin{array}{l}\text { Boys and girls have to participate in how to plan } \\
\text { the new educational scenarios, the new city } \\
\text { scenarios. How can we encourage this } \\
\text { participation? }\end{array}$ & 116 & 87 & 13 \\
\hline 6 & 05/06/2020 & Inclusive democracy and political engagement & 101 & 80 & 11 \\
\hline 7 & $19 / 06 / 2020$ & $\begin{array}{l}\text { Children's communication and participation. } \\
\text { Strategic alliance? }\end{array}$ & 76 & 60 & 10 \\
\hline 8 & 03/07/2020 & Families educating in citizenship & 74 & 45 & 5 \\
\hline 9 & $17 / 07 / 2020$ & $\begin{array}{l}\text { Reviewing inputs and devising challenges in } \\
\text { \#participatorychildhood }\end{array}$ & 58 & 40 & 13 \\
\hline 10 & $16 / 10 / 2020$ & $\begin{array}{l}\text { What next? Let's have a coffee } \\
\text { \#participatorychildhood }\end{array}$ & 97 & 55 & 7 \\
\hline 11 & $06 / 11 / 2020$ & $\begin{array}{l}\text { Participatory democracy: What can we learn } \\
\text { from social movements? }\end{array}$ & 86 & 55 & 10 \\
\hline 12 & $19 / 02 / 2021$ & $\begin{array}{l}\text { How do we move towards authentic child } \\
\text { participation? Recognition of children as agents. }\end{array}$ & 132 & 80 & $x$ \\
\hline 13 & $16 / 04 / 2021$ & $\begin{array}{l}\text { How to strengthen the identity of participation } \\
\text { groups? Video stories and other creative } \\
\text { languages as expressive tools for participation. }\end{array}$ & 79 & 65 & $x$ \\
\hline 14 & $11 / 06 / 2021$ & $\begin{array}{l}\text { Children, participation, and the environment: } \\
\text { Are children leading the way towards } \\
\text { eco-citizenship? }\end{array}$ & 101 & 70 & 14 \\
\hline \multirow[t]{2}{*}{15} & $08 / 10 / 2021$ & $\begin{array}{l}\text { Strengthening child participation for the } \\
\text { achievement of the SDGs }\end{array}$ & 91 & 60 & 10 (+6 chat read) \\
\hline & & AVERAGE & 98 & 67 & 11 \\
\hline
\end{tabular}


female technicians responsible for promoting participation in their own municipality, plus one municipal councillor. On average, each participant attended between 5 to 8 meetings, with an average of 270 attendants from 219 Spanish municipalities.

This article adopts the methodology of systematisation of experiences (Aguiar, 2013; Barnechea \& Morgan, 2010; Jara, 2012, 2018; Mera, 2019) that allows us to reconstruct and reflect on practice, through which we interpret events in order to understand them. Our object of study is the experience of the "coffee space," an intervention designed to promote the inclusion of children as subjects of rights, political subjects, and active citizens. Through the systematisation of the experience of the coffee space, we will critically analyse the experience to review and improve it, rethink meanings and signifiers that have guided and shaped the experience for it to generate a reflective meeting and amplify the opportunities to include children and adolescents in decision-making. Specifically, three objectives are pursued:

1. To understand the processes that emerge in the development of the "coffee meeting" experience, sustaining it.

2. To know the representation that the participants make of this space.

3. To identify the advances that participants' acknowledge having made as to the inclusion of child participation in the municipality.

The informants who generate knowledge in the practical experience of the coffee space, as well as contribute to its systematisation, are: municipal professionals and technicians who have been involved in at least one "coffee meeting"; research partners who participated in coffee meetings and were part of the monitoring team; and the 23 members of the research team, including four members from the University of Barcelona who also led the experience.

Qualitative data collection techniques bring us closer to reconstructing the experience of the coffee meetings, providing a deeper understanding of the importance and meanings that participants attached to them (Mera, 2019). For the present systematisation, collection techniques were as follows: 42 surveys were collected after the 5 th coffee meeting and 43 surveys after the 14th coffee meeting; there were 16 minutes of monthly planning meetings between partners and the team at the University of Barcelona; 12 newsletters were written by the promoters; 10 summaries generated by the IAEC. All the questions posed by participants about the proposed theme have been considered. The diversity of sources allows us to reconstruct and reinterpret the experience according to the different perspectives involved.

The information gathered was analysed using a combination of two qualitative techniques. On the one hand, we carried out a frequential lexicometric analysis that identifies words with the same origin, focusing on their essential significance through the software for lexicometric analysis Iramuteq (de Alba, 2004; Molina-Neira et al., 2017; Ruiz, 2017).On the other hand, we conducted an inferential content analysis based on the constant comparison method (Corbin \& Strauss, 2008; García, 2019) to identify the codes used by the informants for understanding the meanings and senses they give to the experience. Based on the inductive analysis, those dimensions that informants value and consider relevant for the development of this practice were identified, and fragments of narratives have been selected to illustrate the meanings attributed to them.

The process of this systematisation study includes informed consent and procedures to guarantee anonymity and confidentiality under the European General Data Protection Regulation (Regulation EU 2016/679 of the European Parliament and of the Council of 27 April 2016), as well as the research team's commitment to return the knowledge generated to the community.

\section{Results and Discussion}

The results are organised into three different units of analysis: (a) reconstruction of the experience, a collective process; (b) joint interpretation, meanings, and senses of the coffee space; and (c) contributions and knowledge generated.

\subsection{Reconstructing the Experience: A Collective Process}

This defining process takes shape through constant joint dialogue and review between the research team and partners. The opinions and evaluations offered by the participants at different times are also taken into consideration. This evolution is accompanied by many uncertainties and questions that define each encounter and course of action: What can we offer? What issues are you interested in addressing? What do they need right now? For how long and how often? Who will organise and energise them? How will attendees be allowed to intervene? How will the sessions be run? How to share the knowledge generated? How to present the topics? Questions stemmed from the desire to generate a useful space for those professionals who work daily with and for childhood participation.

Given that "Let's Have a Coffee \#participatorychildhood" was born during the pandemic, it has been developed through virtual means. Online connectivity has made it easier for the entire target community to attend the meeting and opened the door to greater representativeness and diversity. However, adapting to this environment meant, especially in the first meetings, revising and adjusting the process. This was due to the novelty of virtual communication and the need for training for both promoters and participants.

The elements that shape each session of the "coffee meeting" are described below: 
1. Review and determination: The development team and its partners analyse a meeting and adjust elements for the next one. After the first eight coffee meetings, the working and review sessions required online meetings with the IAEC and CAI-UNICEF; subsequent sessions focused on reviewing the contents and dynamics of each meeting. The aspects that were analysed before each coffee meeting were:

- Date and time: Initially, coffee meetings were held weekly, an immediate response to the general climate of uncertainty people were living in, but the workload for the development team was unsustainable. This was followed by meetings every fortnight. The situation has now somewhat normalised. From the 10th meeting onwards it started to be held monthly.

- Themes: Topics for subsequent meetings arise from asking ourselves: What have participants suggested? What is interesting? Where can the research team contribute? Answers must emerge from previous coffees meetings and dialogue with partners, and thus the topic for the next meeting is defined.

2. Drafting the coffee meeting announcement: A few lines are written to present the topic from a theoretical and practical standpoint and raise challenges and questions to participants. Partners help clarify and bring these lines of enquiry closer to the municipal reality. The call is sent by e-mail to participants of previous meetings and the registration form is activated on the project website. Especially for the first few meetings, partners use their networks to raise awareness to the meetings.

3. Communication with the community: The topic of the coffee meeting is announced, participants register in the meeting using a short form, and send in questions or experiences to guide the session. On occasions, as a result of their experiences, they are invited to share their experience in the coffee space and encourage exchange. Registrations have never been intended to gather personal data beyond name and e-mail address, nor were they intended to monitor attendance for accreditation purposes.

4. Session development: On the day of the meeting, two team members follow up on e-mails and registrations to resolve any possible access issues. Initially, the sessions were moderated entirely by the same member of the team. After a few coffee meetings, and to give visibility and responsibilities to different members of the team, the moderator was changed and, in some sessions, two people were in charge of moderating the same meeting. A meeting can be divided into four main parts:

- Welcome session: The meeting is introduced and technical indications are given. In the first few meetings, partners were given time and the space to introduce themselves.

- Theoretical framing: Space is given for suggestions and questions to emerge. The aim is to offer theoretical argumentation and generate exchange, dialogue, and reflection. This space has been allocated a duration of about 20 to 40 minutes.

- Reflection, debate, and exchange: This is the core of any meeting, nourished by participants' reflections, doubts, and contributions based on their practical involvement. In more recent meetings, some municipalities have been asked to share their experiences, thus generating dialogue based on specific experience. This decision stems from the knowledge and recognition that municipalities are successfully developing practices related to some of the topics discussed and to make space for a more dynamic dialogue. This space has been allocated a duration of about 50 to 60 minutes.

- Ending session: The meeting concludes by gathering some ideas, thanking the participants for their contributions, announcing the date of the next meeting, and sharing news related to the project. Partners can also conclude the session themselves with a brief intervention.

5. Documentation: After each meeting, the team writes a newsletter with the key ideas generated from the meeting. This is posted on the project website. Minutes of the meeting are drafted as internal team material. Likewise, there is a constant follow-up of e-mails, since evaluations, comments, or experiences may be used in future sessions.

The review process allows us to establish those elements whereby participants feel that a bond has been built between all those who have attended the meetings. These elements are: the newsletter that allows us to visualise the contents generated during each session; the brief registration form prior to each meeting, where participants can leave questions or examples of practices; the space for exchange and collective construction during each session. Figure 1 illustrates the different moments and actions that today structure, from the perspective of the research team, the \#participatorychildhood coffee meeting.

\subsection{Joint Interpretation, Meanings, and Senses of the Coffee Space}

Participants have constructed representational cores around their involvement in the coffee meetings. A survey was carried out to ask municipal technicians and researchers what their representation of the space was 


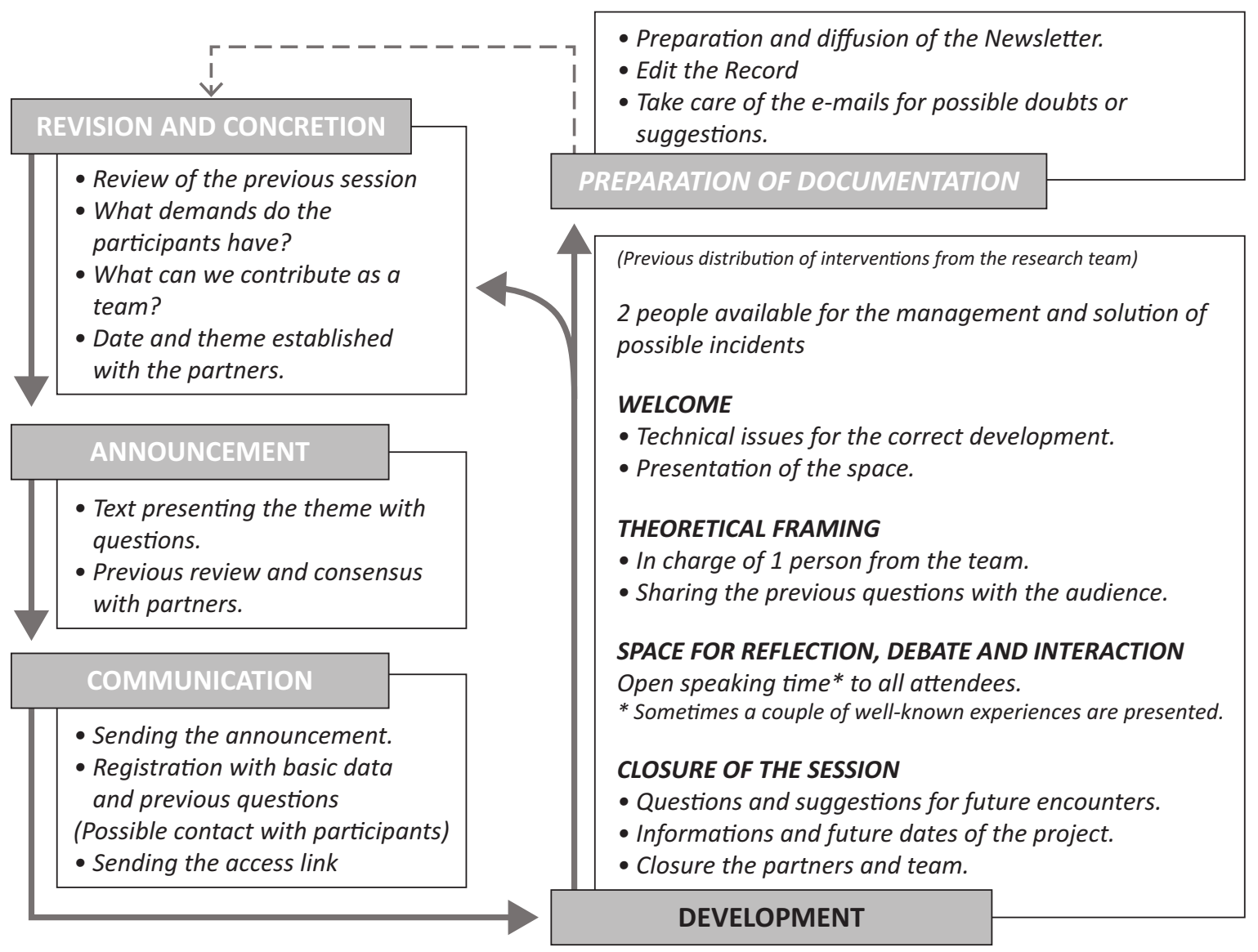

Figure 1. Reconstructed sequence of moments and actions that structure the coffee meetings.

following the question: "When I think of the coffee space, the three words that come to mind are..."

If we look at the contributions made by the 43 municipal professionals (see Figure 2), the words that are most present are sharing (23 occasions), experience (16), participation (9), and learning (12). Meanwhile, for the 18 members of the research team, the most repeated words are sharing (11), experiences/experiential (4), meeting (4), participation (3), and learning (3).

Based on input from municipal technicians and researchers, five representation cores are identified:

1. Sharing, learn, learning: Representation derives from the action that has taken place in the coffee space, which is deemed a sharing space/moment that has made learning possible. Participants mentioned: "sharing, learning and generating knowledge" (T, 41); "sharing, learning, dialogue, respect" $(U, 4)$.

2. Knowing, knowledge: Value is placed on what the space offers in terms of knowledge and the construction of shared knowledge. Participants mentioned: "to know, share, build" (T, 22); "relationships, experiential knowledge" $(U, 13)$.

3. Experiences: Value is placed on the content that has been the main focus of the meeting from an exchange perspective. Participants men- tioned: "experiences, good practices and shared resources" $(T, 18)$.

4. Participation: The thematic specificity of the practical community that comes together to talk about childhood and participatory experiences is emphasised. Participants mentioned: "experience, participation and organisation" (T, 29).

5. Network: Representation derives from what is generated in the participant after the reflective meeting and exchange with other people with the same concerns, interests, and/or motivation around child and adolescent participation in municipalities. Participants mentioned: "sharing, network reflections, generating cohesion of discourse" (T, 20); "sharing experiences, learning, professional networks" (U, 17).

Both groups agree on the meaning of the coffee meeting as an act of sharing that produces knowledge and learning. Among the municipal technicians, the representative core of experiences and participation is more significant than in the research team, for it means, to a greater extent, the opportunity for professional exchange.

Finally, it is interesting to note the adjectives that have been attached to the experiment. On the part of the professional technicians, the following adjectives emerge, from most to least frequent: interesting (4); 
good (2); practical (2); adequate (1); friendly (1); necessary (1); professional (1); theoretical (1); and useful (1). In the case of researchers these are: professional (2); collective (1); experiential (1); global (1); good (1); informal (1); and virtual (1).

The coffee meeting has proven to be a space that both groups value. It should be noted that they emphasise different aspects, which is why they are presented in different ways. When professionals were asked about the degree of usefulness and satisfaction with the meeting, $36.6 \%$ gave the space a score of 9 out of 10 , followed by $24.39 \%$, who gave it the highest score, and $19.51 \%$, $17.07 \%$, and $2.43 \%$, who gave it scores of 8,7 , and 6 , respectively.

So far, meetings have been deemed agile, brief, "entertaining," "approachable," and interesting in the way they generate proximity; it is perceived that everyone shares and is open to explaining what they need. One participant elaborated: "[The meeting] is entertaining and approachable, with interesting topics, without being overly theoretical" $(T, 18)$.

The content of the meetings have been enriching, useful to "take away ideas" as well as "theoretical and methodological contributions": "The learning and knowl-

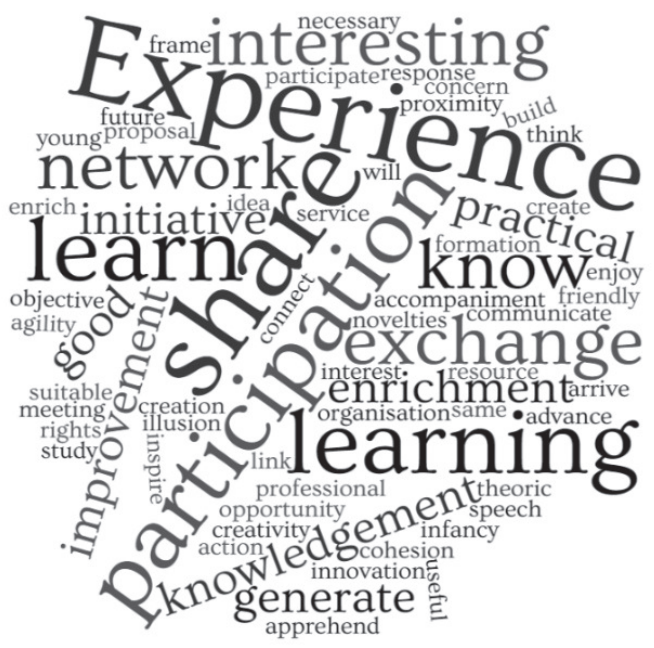

\begin{tabular}{|c|c|c|c|c|c|c|c|c|c|}
\hline \multicolumn{6}{|c|}{ NAME } & \multicolumn{2}{|l|}{ VERB } & \multicolumn{2}{|l|}{ ADJECTIVE } \\
\hline Experience & 16 & creation & 1 & interest & 1 & share & 23 & interesting & 4 \\
\hline participation & 9 & creativity & 1 & young & 1 & learn & 6 & good & 2 \\
\hline learning & 6 & rights & 1 & frame & 1 & know & 5 & practical & 2 \\
\hline exchange & 5 & speech & 1 & novelties & 1 & generate & 2 & suitable & 1 \\
\hline network & 5 & meeting & 1 & objective & 1 & apprehend & 1 & friendly & 1 \\
\hline knowledgement & 3 & link & 1 & opportunity & 1 & advance & 1 & same & 1 \\
\hline enrichment & 2 & study & 1 & organisation & 1 & communicate & 1 & necessary & 1 \\
\hline initiative & 2 & formation & 1 & concern & 1 & build & 1 & professional & 1 \\
\hline improvement & 2 & future & 1 & proposal & 1 & create & 1 & theoric & 1 \\
\hline action & 1 & idea & 1 & resource & 1 & enjoy & 1 & useful & 1 \\
\hline accompaniment & 1 & illusion & 1 & response & 1 & enrich & 1 & & \\
\hline agility & 1 & infancy & 1 & service & 1 & inspire & 1 & & \\
\hline proximity & 1 & innovation & 1 & will & 1 & arrive & 1 & & \\
\hline cohesion & 1 & & & & & participate & 1 & & \\
\hline & & & & & & think & 1 & & \\
\hline & & & & & & connect & 1 & & \\
\hline
\end{tabular}

edge shared by the research team and the municipalities, the exchange of tools and good practices, have been very enriching and nourishing" ( $T, 6)$.

The meetings have been so far regarded as spaces that strengthen one emotionally, since they respond to a need to reflect within a group, allowing one to see beyond their professional work and share their feelings: "The great need to share views, experiences and difficulties that arise in the daily work I do....[Here you don't] feel alone" (T, 32).

Finally, the meetings have been praised for the close dialogue between universities and municipalities they facilitate:

The cohesion of a network discourse can only be effective if it is validated through dialogue between the real experiences of the municipalities....For this reason, I value...being able to share university studies and theories on the pedagogy of child participation with the contrasted reality of the municipalities that carry out the real experience. $(T, 20)$

The research team highlighted other aspects associated with the origin of the initiative, the context in which it

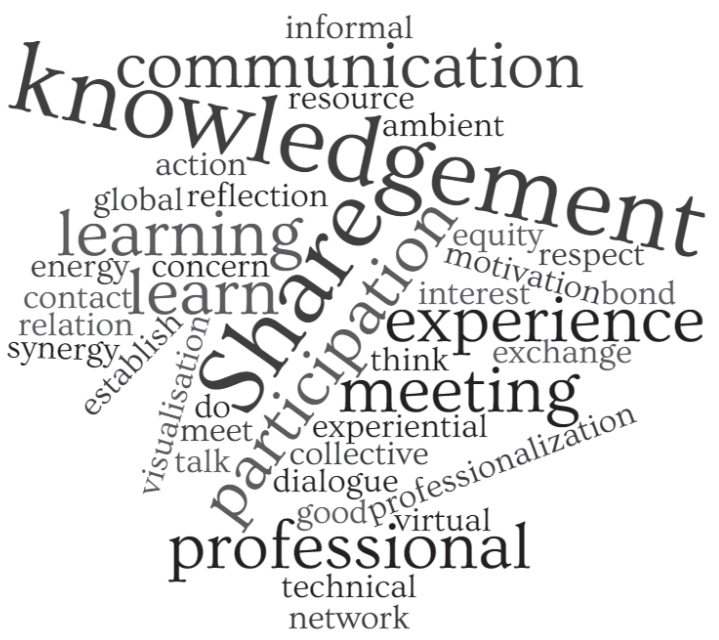

Figure 2. Word clouds and frequency tables according to the answer to the question: "When I think of the coffee space, the three words that come to mind are..." 
was developed, and its continuity based on participants' feedback:

- Timeliness, stability, and regularity: "The continuity and opportunity [the meetings] have offered during these difficult times, amid a pandemic, the content and shared experiences should...be valued. They have allowed us all to learn" $(U, 10)$.

- Climate generated, the creativity involved, and organization: "I think it has been a very creative and stimulating initiative, especially in times of [a] pandemic" (U, 7).

- Diversity, horizontality; a plural participatory space: "The will to make these participatory spaces and to give a voice to people who are working at the municipal level on issues of child participation. Also, the diversity of trainers and the expertise in these issues" $(U, 6)$.

In these interpretations of the coffee space, those involved say that they feel they learn in optimal and satisfactory conditions, and are connected through their interest in the theme and the climate generated. In this way, they overcome the sense of defeat or loneliness that some feel in the face of the challenge of child inclusion in municipalities. Consequently, the definition of the coffee space goes beyond the original intention and is configured as a reference to advance towards the goal of inclusion, since participants recognise themselves as a group and weave networks by sharing feelings, knowledge, and experiences.

\subsection{Contributions and Knowledge Generated}

Our coffee space has been associated with a space for knowledge and learning. It has made it possible to consolidate and update existing knowledge and create/acquire new one. One participant highlights in a very generic way the contributions it has made for him: "knowledge of other experiences, opening up my work perspective, broadening my knowledge, taking on new work challenges" $(T, 4)$.

It has been a concern of the development team and their partners to always know that the space was useful and offered working elements to promote the inclusion of children as citizens in decision-making processes. The different contributions generated by the learning community are identified below, ranging from conceptual knowledge to know-how and handling oneself:

- Representation of children and adolescents as subjects of rights, political subjects, and active actors in their municipality: A change of outlook towards children, considering them as citizens capable of being involved in constructing the municipal model, is encouraged. Taking the CRC as a framework, we go further and highlight the need to include children in the configuration of institutions and the municipality, as underlined in the following participant's quote:

Incorporate the Convention's approach in the different programmes: Involve children and adolescents in the municipality's projects. $(T, 39)$

- Readjusting the meaning of children's participation to make it inclusive, proactive, and impactgenerating: A concept of participation is recognised that goes beyond giving a voice or being listened to, which should be closer to a protagonist's participation far from adult-centrism. The need to include the participation of children and adolescents at different stages of the participatory process is highlighted, opening up more opportunities to influence and transform:

[The meetings] have allowed us to learn about approaches that focus on participation beyond the simple gathering of opinions of boys and girls, moving towards a more transformative participation and governance. $(T, 8)$

- Addressing child participation in the municipality in a cross-cutting manner and within the socioeducational ecosystem: The promotion of children's participation in the municipality needs to be incorporated from all government areas, not only as a commitment to education but also as the inclusion of active citizenship. It also requires going beyond the school and involving more actors and more children:

[There was a] comprehensive approach to the importance of cooperation within different municipal areas and social agents of the municipality. $(T, 6)$

- Discovery of good practices and different ways of doing things: Contributions related to how to promote participation from other paths and innovative actions that open up a range of possibilities in a given municipality were highlighted. Participants especially recognise practical contributions of a methodological nature (know-how):

Knowledge of other realities, innovative approaches, participatory methodology, meeting place for professionals, relaxed ambience. $(T, 18)$

- Strengthening motivation, recognising oneself within a network of professionals who share hopes and challenges that encourage them to continue: Reports show that sharing with others has revitalised the desire to continue doing things and the 
value of the work our participants do. Emotional and professional links and connections have been generated, anchored on companionship, which has helped mitigate feelings of loneliness:

Motivation (you are not alone), learning from the experiences, tools and networking, the possibility of contacting colleagues from other cities that we might be interested in contacting for discussing projects. $(T, 7)$

The coffee space offers elements for professional training: Here, participants claim to have acquired knowledge, skills, and confidence to perform at their best. This element of self-confidence is especially important, for it comes with these professionals recognising themselves as a professional network, which brings trust into their daily work. The perceived learnings furnish these professionals with new parameters from which to think about the inclusion of children and design innovations to promote this includion.

\section{Conclusion}

The coffee meetings emerged in a pandemic context to avoid that the inclusion of children in decision-making in their city took a step backwards. The experience has been consolidated over time and was transformed by participants' adjustments. It should be noted that, for its participants, our coffee meetings have become something more entirely: Reviewing referential frameworks, the lived process of the experience is identified as "a learning community" and a "community of practice."

Communities in which people learn, share knowledge or professional experiences, and solve problems collaboratively are a reality (Sanz, 2012). For this experience, we opted to establish a "community of value" where knowledge can be shared. The coffee space is also a "community of learning," as those who participate and become involved with the research team learn and teach. Finally, this is too a "community of practice," as these groups share a concern or passion for something they do and acquire tools to do it better, interacting regularly (Wenger, 2014). If we pay attention to the three characteristics of "community" as proposed by Wenger (2014), we recognise the elements that shape the coffee space:

- Domain: a common interest that connects and holds the community together. The coffee space brought together municipal technicians who were interested in ensuring that children's participation did not regress in times of crisis. The community needed to know how to continue promoting participation in a changing scenario where living conditions altered our daily lives and opportunities to participate.

- Community: A community is bound by the shared activities it pursues (e.g., meetings, discussions) around a common domain. It has been shown how the elements introduced in the coffee experience promoted bonding before, during, and after the encounter. They were facilitating activities that helped one stay connected in complex times without requiring excessive time dedication.

- Practice: Members of a community of practice are practitioners. What they do involves their participation in the community and what they learn from the community affects what they do. Participants from our coffee meetings recognised that they were amidst a process of revising their frameworks, consolidating them while also questioning them. This knowledge had a practical aspect with specific actions that could be implemented and transferred. That were visualised as opportunities.

It should be noted that this learning community is made up of people who approach child participation from different realities, points of reference, and backgrounds. On the other hand, as a learning community, the coffee space seeks to be a meeting place for collective construction, hoping that each person involved manages to broaden, deepen, and establish their reference frameworks to include the participation of children and adolescents in their professional horizons. In the process of shaping itself as a learning community, there have been two other elements around the coffee space that have strengthened it:

- Innovation: New references to the inclusion of children as citizens have been sought. In the coffee space, possible responses to situations were collectively generated from ideas that were not previously available or accessible. Furthermore, "new" questions have been posed that have changed participants' views of children's participation and their inclusion as citizens.

- Well-being: Feeling accompanied and heard in the face of adversity (the complexity of life during the pandemic) generated proximity between participants, who were also able to establish relational bridges on an issue in which they have felt neglected. Recognising a shared identity renews hopes and generates new expectations based on trust and the value of children's participation within the municipality.

The design, organisation, and implementation of the weekly coffee meeting brought about issues related to the approach and meaning of the meetings, timing, contents, technological and operational needs, responsibilities of those involved, and co-participation. We unanimously understood from the outset that the effort would be worthwhile. The topics to be addressed, the dissemination and registration process, the availability of documents to support the sessions, the availability and encouragement of those who wished to speak, 
and the flexibility in the duration and dates of the sessions were variables decided in a democratic and inclusive process. Spokespersons from IAEC and CAI-UNICEF, researchers from the four universities participating in the project, elected officials, and technical figures make up a highly beneficial, horizontal, and transparent space, both emotionally and in terms of collaborative learning. Meeting, seeing each other, expressing ourselves during these complicated days has been somewhat healingand learning from each other, based on specific demands and diverse experiences, pedagogical.

We have verified that partners, elected representatives, municipal technicians, and team researchers found the experience very positive because of the number and diversity of participants, the quantity and quality of the interventions, and the demand for new themes and meetings. This is confirmed by the words of recognition expressed by all participants. At a time of crisis, in which social deprivation has made it especially difficult to undertake our work in usual circumstances, the coffee space has been an opportunity to address important social questions that needed to be answered quickly. More importantly, it has also provided room to rethink the future of our institutions in favour of childhood participation.

Generating initiatives such as the coffee space, in which professionals who are directly and closely linked to child participation in their municipalities can raise and resolve their doubts and concerns, is beneficial to their professional development. They also promote a shared vision of children as present and active citizens. Sharing and exchanging opinions and experiences has enriched the confidence of involved participants in their work, allowing them to weave networks that will favour opportunities for the participation of children as provided by municipal administrations. Naturally, moments like those provided in the coffee meetings shouldn't be the only step being taken for the recognition of children's citizenship rights and their civic participation. Nevertheless, the coffee space has turned out to be a good strategy to train and accompany professionals who share a common objective: to strengthen the participation of children in their municipalities.

The coffee meetings have been a formative space: They have generated professional capacity, strengthened the understanding of children's participation and their role as citizens, and favoured the inclusion of children's opinions in municipal decisions. Participants will be encouraged to replicate the experience in their municipal professional teams in order to better adjust it to each municipality's reality. That will also allow sharing the leading role of children in local participation processes.

Regarding the potential of the "Let's Have a Coffee \#participatorychildhood" initiative, we propose that it is necessary to maintain it live for as long as it is relevant and demanded by its participants, for the experience has proven useful in engaging participants by finding answers to their practical problems and needs. Therefore, this community of learning and practice has an interesting future.

\section{Acknowledgments}

The authors acknowledge funding by the Ministry of Science and Innovation of the Government of Spain, the European Regional Development Fund, and the State Research Agency of the Government of Spain, in support of the research project Childhood and Participation: Diagnosis and Proposals for Active and Inclusive Citizenship in the Community, Institutions, and Governance (RTI2018-098821-B-I00; https://www.ub.edu/ infanciayparticipacion).

\section{Conflict of Interests}

The author declares no conflict of interests.

\section{References}

Aguiar, J. G. (2013). Sistematización como método de investigación cualitativa: Un uso nuevo de las cosas conocidas [Systematization as a qualitative research method: A new use of known things.]. Educación y Futuro Digital, 6, 29-41. https://cesdonbosco.com/ numeros-publicados/educacion-y-futurodigital.html

Barnechea, M., \& Morgan, M. (2010). La sistematización de experiencias: Producción de conocimientos desde y para la práctica [Systematization of experiences: Production of knowledge from and for practice.]. Tendencias y Retos, 15, 97-107. http://www.ts.ucr.ac. $\mathrm{cr} / \mathrm{bv} / \mathrm{rev}$-tendencias.php

Corbin, J., \& Strauss, A. (2008). Basics of qualitative research. Techniques and procedures for developing grounded theory. SAGE. https://doi.org/10.4135/ 9781452230153

Crowley, A., Larkins, C., \& Pinto, L. (2021). Listen-actchange: Council of Europe Handbook on children's participation for professionals working for and with children. Council of Europe. https://rm.coe.int/ publication-handbook-on-children-s-participationeng/1680a14539

de Alba, M. (2004). El método ALCETE y su aplicación al estudio de las representaciones sociales del espacio urbano: El caso de la ciudad de México [The ALCESTE method and its application to the study of the social representations of urban space: The case of Mexico City]. Papers on Social Representations, 13(1), 11-20. https://psr.iscte-iul.pt/index.php/PSR/ article/view/357

Del Pozo, J. M. (2020). Ciudad educadora y cultura ciudadana [Educating city and civic culture]. In R. B. Coppini \& E. Palacios (Eds). Estrategias innovadoras en la formación de docentes en la construcción de paz [Innovative strategies for teacher training in peace 
building] (pp. 87-99). Cátedra Medellín-Barcelona de la Fundació Kreanta.

Dos Santos Figueiredo, Y. D., Prim, M. A., \& Dandolini, G. A. (2018). Educating city: A media for social innovation. In L Pereira, J. Carvalho, P. Krus, M. Klofsten, \& V. De Negri (Eds.), Proceedings of IDEAS 2019 (pp. 251-260). Springer. https://doi.org/10.1007/978-3030-55374-6_25

García, P. D. (2019). El método comparativo constante y sus potencialidades para el estudio de políticas educativas para la escuela secundaria en Latinoamérica [The constant comparative method and its potential for the study of educational policies for the secondary school in Latin America]. Revista Latinoamericana de Educación Comparada, 10(15), 27-43. https://www. saece.com.ar/relec/numero15.php

Giménez Romero, C. (2020). Letter to councillors about city, culture and education. In Monograph: City, culture and education (pp. 8-15). International Association of Educating Cities.

Jara, O. (2012). Sistematización de experiencias, investigación y evaluación: Aproximaciones desde tres ángulos [Systematization of experiences, research and evaluation: Three different approaches]. Educación Global Research, 1, 56-70. http://educacion globalresearch.net/issue01jara

Jara, O. (2018). La sistematización de experiencias: Práctica y teoría para otros mundos posibles [The systematization of experiences: Practice and theory for other possible worlds] (1st ed.). Fundación Centro Internacional de Educación y Desarrollo HumanoCINDE.

Liebel, M. (2020). La niñez popular. Intereses, derechos y protagonismos de los niños y niñas [Popular childhood. Interests, rights and protagonism of children]. Catarata.

Mera, A. (2019). La sistematización de experiencias como método de investigación para la producción del conocimiento [The systematization of experiences as a research method for the production of knowledge]. Rehuso, 4(1), 99-108. https://revistas.utm.edu.ec/ index.php/Rehuso/article/view/2143

Molina-Neira, J., Barriga-Ubed, E., \& Gámez Ceruelo, V. (2017). Representaciones sociales de los adolescentes catalanes sobre la participación política en democracia [Social representations of catalan adolescents on political participation in democracy]. International Journal of Sociology of Education, 6(1), 85-109. https://doi.org/10.17583/rise.2017.2472

Moosa-Mitha, M. (2019). The political geography of the "best interest of the child." In T. Skelton \& S. C. Aitken (Eds.), Establishing geographies of children and young people (pp. 295-314). Springer.

Percy-Smith, B. (2018). Participation as learning for change in everyday spaces: Enhancing meaning and effectiveness using action research. In C. Baraldi \& T. Cockburn (Eds.), Theorising childhood: Citizenship, rights and participation (pp. 159-186). Palgrave Macmillan.
Percy-Smith, B., Thomas, N., Batsleer, J., \& Forkby, T. (2019). Everyday pedagogies: New perspectives on youth participation, social learning and citizenship. In J. Batsleer, P. Loncle, A. Pohl, \& A. Walther (Eds.), Struggling for participation: Practices, power and pedagogies of young people in the public (pp. 179-198). Routledge.

Pose, H., \& Caride, J. A. (2019). A educación, compromiso e responsabilidade dos concellos democráticos en Galicia (1978-2018) [Education, commitment, responsibility and democratic local government in Galicia, 1978-2018]. Sarmiento: Revista Galego-Portuguesa de Historia da Educación, 23, 161-182. https://doi.org/10.17979/srgphe.2019.23. 0.5885

Rudner, J. (2017). Educating future planners about working with children and young people. Social Inclusion, 5(3), 195-206. https://doi.org/10.17645/si.v5i3.974

Ruiz, A. (2017). Trabajar con Iramuteq: Pautas [Working with Iramuteq: Guidelines]. Dipòsit Digital de la Universitat de Barcelona. http://diposit.ub.edu/dspace/ handle/2445/113063

Sanz, S. (2012). Comunidades de práctica: El valor de aprender de los pares [Communities of practice: The value of learning from peers]. EdiUOC.

Save the Children Sweden. (2020). A mapping of child participation initiatives in public decision making and monitoring processes. https://bit.ly/3yGT4hm

Subirats, J. (2008). Governance and education. In Education and urban life: 20 years of educating cities (pp. 227-235). International Association of Educating Cities.

Trilla, J., \& Novella, A. (2011). Participación, democracia y formación para la ciudadanía. Los consejos de la infancia [Participation, democracy and citizenship education. Local children's councils]. Revista de Educación, 356, 23-43. https://bit.ly/3mlZzRD

United Nations Convention on the Rights of the Child. (2009). General comment no. 12 (2009): The right of the child to be heard. https://www.refworld.org/ docid/4ae562c52.html

United Nations Convention on the Rights of the Child. (2016). General comment no. 20 (2016) on the implementation of the rights of the child during adolescence. https://www.refworld.org/docid/589dad3d4. html

Wenger, E. (2014). Communities of practice: A brief introduction. Wenger-Trayner. https://wenger-trayner. com/wp-content/uploads/2013/10/06-Briefintroduction-to-communities-of-practice.pdf

Wilks, J., \& Rudner, J. (2013). A voice for children and young people in the city. Australian Journal of Environmental Education, 29(1), 1-17. https://doi.org/ 10.1017/aee.2013.12

Wyness, M. (2013). Global standards and deficit childhoods: The contested meaning of children's participation. Children's Geographies, 11(3), 340-353. https:// doi.org/10.1080/14733285.2013.812280 


\section{About the Authors}
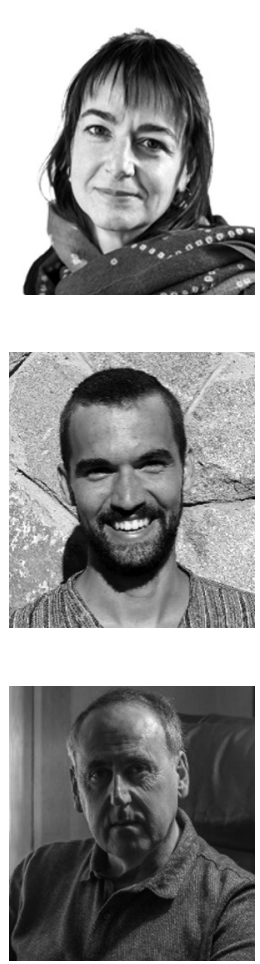

Ana M. Novella Cámara is a professor in the Department of Theory and History of Education at the University of Barcelona. She holds a PhD in philosophy and educational sciences from the University of Barcelona and is a member of the consolidated research group Grupo de Investigación en Educación Moral (GREM). Her lines of research are citizenship, participation and socio-educational fields, governance, childhood and citizen participation, education in values, participatory methodologies, and co-production. She is currently co-principal investigator of the R\&D project RTI2018-098821-B-I00 and member of the Sociedad Iberoamericana de Pedagogía Social (SPIS).

Ferran Crespo i Torres is a pre-doctoral researcher in training at the Department of Theory and History of Education at the University of Barcelona. Student of the PhD programme in education and society at the University of Barcelona, he belongs to the research group in moral education (GREM). His lines of research and interests are linked to environmental education and children's participation, and governance, childhood, and free time. He participates in the R\&D project RTI2018-098821-B-I00.

Héctor Pose Porto holds a PhD in psychopedagogy from the University of A Coruña. He has participated as a researcher in several socio-pedagogical studies, speaker in numerous congresses, courses and conferences on sociocultural animation and cultural management, as well as published articles and books on associationism, sociocultural animation, theatre animation, children's participation, etc. He has worked as an education and culture technician in the Council of Malpica (1991-2000) and is currently a professor in the Faculty of Education at the University of A Coruña. He belongs to the research group Política Educativa, Historia e Sociedade (UdC). 